\title{
THE NECESSITY OF REVISING PRIMARY SCHOOL CONTENT OF PROBABILITY IN EGYPT TO ENHANCE STUDENTS' PROBABILISTIC REASONING
}

\author{
Samah Gamal Ahmed Elbehary \\ Graduate School for International Development and Cooperation, Hiroshima University, Japan \\ dr.samalelbeh7ary@yahoo.com
}

In the context of developing countries, Egypt as well, substantial importance is always assigned to textbooks. Besides, many teachers place priorities on discussing its activities. Therefore, in the case of probability, it is crucial to reflect on textbooks' discourse for identifying the possible opportunities given to students to enhance their probabilistic reasoning. From this perspective, an OntoSemiotic Approach (OSA) combined with Batanero et al's. (2016) description of main interpretations of probability has been employed to deduce and categorize the essential entities of probability longitudinally across grades. As a result, the current content can foster students' procedural knowledge of objective probability with little attention to the epistemic side that views probability as a personal degree of belief. Consequently, it is important to revise the primary school content of probability through implementing some basic probabilistic concepts (e.g., the law of large number and conditional probability).

\section{INTRODUCTION}

Long discussion through mathematics education platform tends to focus on developing students' mathematical thinking that has deterministic and logical characteristics. However, enhancing students' probabilistic reasoning is the central concern in the case of probability. Probabilistic reasoning refers to make a decision under uncertainty whenever the randomness and variability are recognized (Falk \& Konold, 1992; Savard, 2014). Hence, the teaching of probability seeks to overcome students' deterministic thinking and accept the existence of chance in nature. In this regard, students and teachers are faced by some tensions and challenges such as connections among mathematics, statistics, and probability. In Egypt, like several other countries, statistics and probability are included in the algebra course which makes it difficult for the students to separate deterministic thinking and the idea of chance in probability (Dvořáková et al., 2017).

Although, in the context of developing countries, many teachers place priorities on discussing textbook activities. these textbooks have been criticized in terms of presenting a too narrow view of probability (Batanero et al., 2004). Therefore, it is important to reflect on textbooks' discourse for identifying the possible opportunities given to students to enhance their probabilistic reasoning. Consequently, preparing them to face daily life situations that contain uncertainty. From this perspective, the current study aims to analyze the probability content as a part of the primary school mathematics curriculum to interpret its function in enhancing students' probabilistic reasoning.

Consequently, for analyzing the probability content, Onto-Semiotic Approach (OSA) as a practical, semiotic, and anthropological approach to studying the subject through its symbols in an institutional level (Godino, Batanero \& Font, 2007) has been employed. Then, the essential inferred entities of probability have been categorized in the light of Batanero et al., (2016) main interpretations of probability. As a result, the study has revealed some lacking interpretations of probability that may hinder enhancing students' probabilistic reasoning.

\section{METHOD}

Primary school content of probability in the Egyptian context starts from the third grade and continuing until the end of grade 6 . Table 1 summarizes the listed lessons as its sequence according to the national textbook. 
Table 1. Primary school content of probability in Egypt

\begin{tabular}{|c|c|c|}
\hline Grade & Lesson title & the sequence of discussed ideas in each grade \\
\hline $\begin{array}{c}4^{\text {th }} \text { grade, } 2^{\text {nd }} \\
\text { term }\end{array}$ & Probability & $\begin{array}{l}\text { - Quantify the intuitive meaning of probability by a ratio between zero and } 1 \\
\text { - Discuss the meaning of all possible events of a random experiment. } \\
\text { Ask students to calculate the probability of some events using the law of theoretical probability. }\end{array}$ \\
\hline $\begin{array}{c}6^{\text {th }} \text { grade, } 2^{\text {nd }} \\
\text { term }\end{array}$ & $\begin{array}{l}\text { Lesson1: } \\
\text { Random } \\
\text { experiment } \\
\begin{array}{c}\text { Lesson 2: The } \\
\text { probability }\end{array}\end{array}$ & $\begin{array}{l}\text { Define the meaning of the random experiment, and sample space. } \\
\text { Display a tree diagram to represent the sample space for two consecutive experiments. } \\
\text { - } \text { space). } \\
\text { Review the law of theoretical probability; } \mathrm{p}(\mathrm{A})=\mathrm{n}(\mathrm{A}) / \mathrm{n}(\mathrm{S}) \\
\text { - Present the concept of two distinct events (e.g., failure or success). }\end{array}$ \\
\hline
\end{tabular}

Source: http://elearning1.moe.gov.eg/

Consequently, to analyze the previously presented content of probability. First, OSA has been employed to identify its primary entities. According to OSA, the primary entities of probability have defined by situations, propositions, procedures, and language (Godino, 2003; Gómez \& Contreras, 2014) (see Table 2).

Second, in the light of Batanero et al., (2016) currently listed interpretations of probability that should be taken into account in school curricula (intuitive, classical, frequentist, propensity, logical, subjective, and axiomatic meaning). The deducted primary entities of probability have been categorized.

Table 2. Operational definition of OSA entities

\begin{tabular}{|llll|}
\hline Situation & Propositions & Procedures & Language \\
\hline $\begin{array}{l}\text { the probabilistic activities, tasks, and } \\
\text { problems that have been discussed } \\
\text { within the textbook's discourse. }\end{array}$ & $\begin{array}{l}\text { the underlined properties, } \\
\text { relationships, and theories to connect } \\
\text { between the probabilistic concepts. }\end{array}$ & $\begin{array}{l}\text { the applied algorithms and } \\
\text { techniques used to perform a } \\
\text { given situation. }\end{array}$ & $\begin{array}{l}\text { the embedded terms, expressions, notations, } \\
\text { and concepts that appeared implicitly or } \\
\text { explicitly through the discourse. }\end{array}$ \\
\hline $\begin{array}{l}\text { e.g., tossing a coin } \\
\text { e.g., relationship between: the event } \\
\text { and sample space }\end{array}$ & $\begin{array}{l}\text { e.g., } \mathrm{P}(\mathrm{H})=\mathrm{n}(\mathrm{H}) / \mathrm{n}(\mathrm{S}) \\
\text { e.g., randomness, H, P (A), theoretical } \\
\text { probability }\end{array}$ \\
\hline
\end{tabular}

\section{RESULTS}

Through employing the OSA and categorizing the inferred entities of probability, the results have been presented in Table 3. From the previously stated results, generally speaking, it is obvious that primary school content of probability in the Egyptian context puts much more emphasis on addressing the classical and axiomatic meaning of probability. On the other hand, two other different meanings have been approached; the intuitive one when the students first face the probabilistic tasks in grade 3, and students also experience the frequentist meaning, particularly in $5^{\text {th }}$ grade. 
Table 3. Results of analyzing primary school content of probability using OSA

\begin{tabular}{|c|c|c|c|c|}
\hline & Situations & Propositions & Procedures & Term and embedded concepts \\
\hline $\begin{array}{l}\text { Intuitive } \\
\text { meaning }\end{array}$ & $\begin{array}{l}\text { - Use students' daily life context to grasp } \\
\text { certain, possible, and impossible events } \\
\left(\mathbf{3}^{\text {rd }} \mathbf{G}\right) \\
\text { - Discuss the meaning of great and } \\
\text { moderate probability }\left(3^{\text {rd }} \mathbf{G}\right) \\
\text { - Handle students' personal judgments to } \\
\text { determine the degree of probability ( } 4^{\text {th }} \\
\mathbf{G})\end{array}$ & $\begin{array}{l}\text { - Relationship between possible, } \\
\text { impossible, certain events and } \\
\text { personal expectations }\left(3^{\text {rd }} \mathbf{G}\right) \\
\text { - Relationship between types of } \\
\text { events and its probability }\left(3^{\text {rd }}, 4^{\text {th }}\right. \\
\text { G) }\end{array}$ & & 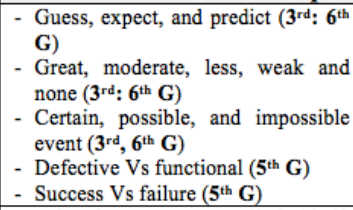 \\
\hline $\begin{array}{l}\text { Classical } \\
\text { meaning }\end{array}$ & $\begin{array}{l}\text { - Discuss the theoretical meaning of } \\
\text { probability through some random } \\
\text { experiments (e.g., tossing a coin, rolling a } \\
\text { dice, gender of a newborn, results of a } \\
\text { football match, spin a spinner) }\left(4^{\text {th }} \mathbf{6}^{\text {th }} \mathbf{G}\right) \\
\text { - Define the sample space not only in a } \\
\text { simple random experiment but also in two } \\
\text { steps trial and assigned probability of } \\
\text { some events }\left(5^{\text {th }} \mathbf{G}, \mathbf{6}^{\text {th }} \mathbf{G}\right) \text {. } \\
\text { - Explain the meaning of the random } \\
\text { experiment }\left(6^{\text {th }} \mathbf{G}\right)\end{array}$ & $\begin{array}{l}\text { - Tossing two coins once is } \\
\text { equivalent to tossing one coin two } \\
\text { consecutive times }\left(6^{\text {th }} \mathbf{G}\right) \\
\text { - Relationship between the sample } \\
\text { space and events }\left(6^{\text {th }} \mathbf{G}\right) \\
\text { - Relationship between the type of } \\
\text { an event and its probability (e.g., } \\
\text { if } A=\phi \text {, then } P(A)=0 / n(S)=0) \\
\left(6^{\text {th }} \mathbf{G}\right) \\
\text { - The probability can be written as } \\
\text { a fractional, decimal, or in the } \\
\text { form of a percentage }\left(6^{\text {th }} \mathbf{G}\right)\end{array}$ & 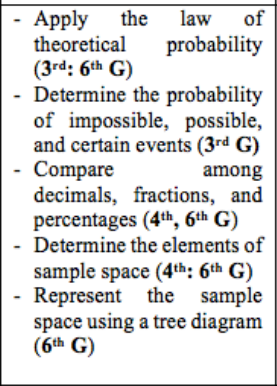 & $\begin{array}{l}\text { - Fair coin, H, T, HH, TT (3rd: 6th G) } \\
\text { - Equally likely, same, symmetric, } \\
\text { and identical (4th: 6th G) } \\
\text { - Ratios, decimals, and percentages \% } \\
\text { (4th G) } \\
\text { - All possible outcomes (4th: 6th G) } \\
\text { - Odd, even, prime, divisible by, } \\
\text { greater or smaller than or between, } \\
\text { and 2-digit number (3rd: 6th G) } \\
\text { - Sample space (S) (5th, 6th G) } \\
\text { - Theoretical probability (5th, 6th G) } \\
\text { - Random experiment (6th G) } \\
\text { - Tree diagram (6th G) } \\
\text { - A, n (A), n (S),P (A), } \varphi,(6 \text { th G) } \\
\text { - inequality } \geq(6 \text { th G) }\end{array}$ \\
\hline $\begin{array}{l}\text { Frequentist } \\
\text { meaning }\end{array}$ & $\begin{array}{l}\text { - Doing a simple random experiment of } \\
\text { tossing a coin } 10,20,50,100 \text { times }\left(5^{\text {th }} \mathbf{G}\right) \\
\text { - Propose a survey to ask students about } \\
\text { preferred sport and language }\left(5^{\text {th }} \mathbf{G}\right) \\
\text { - interpret the favorable cases by knowing } \\
\text { the probability of a small sample }\left(5^{\text {th }} \mathbf{G}\right) \\
\text { - Inference into the probability of a small } \\
\text { sample trough reflecting the population's } \\
\text { characteristics }\left(5^{\text {th }} \mathbf{G}\right)\end{array}$ & $\begin{array}{l}\text { - Relationship between the } \\
\text { experimental and theoretical } \\
\text { probability }\left(\mathbf{5}^{\text {th }} \mathbf{G}\right)\end{array}$ & $\begin{array}{l}- \text { Apply the law of } \\
\text { experimental probability } \\
\left(\mathbf{5}^{\text {th }} \mathbf{G}\right) \text { a } \\
- \text { Calculate the number of } \\
\text { expected times by } \\
\text { knowing the probability } \\
\text { of previous trials }\left(\mathbf{5}^{\text {th }} \mathbf{G}\right)\end{array}$ & $\begin{array}{l}\text { - Regular coin }\left(5^{\text {th }} \mathbf{G}\right) \\
\text { - Survey }\left(\mathbf{5}^{\text {th }} \mathbf{G}\right) \\
\text { - Sample }\left(5^{\text {th }} \mathbf{G}\right) \\
\text { - Experimental probability }\left(5^{\text {th }} \mathbf{G}\right) \\
\text { - Favorable, preferred, and favorite } \\
\quad\left(5^{\text {th }} \mathbf{G}\right)\end{array}$ \\
\hline $\begin{array}{l}\text { Axiomatic } \\
\text { meaning }\end{array}$ & $\begin{array}{l}\text { - Discuss the relationships among all } \\
\text { possibilities of some random experiments } \\
\left(4^{\text {th }}: 6^{\text {th }} \mathbf{G}\right)\end{array}$ & $\begin{array}{l}\text { - For } A \subset \mathrm{S}, 0 \leq \mathrm{p}(\mathrm{A}) \leq 1)\left(\mathbf{4}^{\text {th: }} \mathbf{6}^{\text {th }}\right. \\
\text { G) } \\
\text { - the sum of probabilities for all } \\
\text { possible events }=1\left(\mathbf{4}^{\text {th }} \mathbf{G}\right) \\
\text { - Relationship between the } \\
\text { probability of an event and its } \\
\text { complementary (e.g., success vs } \\
\text { failure, defective vs functional) } \\
\left(\mathbf{4}^{\text {th }}, \mathbf{5}^{\text {th }} \mathbf{G}\right)\end{array}$ & \begin{tabular}{|l} 
- Calculate the probability \\
of a complementary event \\
$\left(\mathbf{4}^{\text {th }} \mathbf{G}\right)$ \\
- Calculate the probability \\
of event A union B $\left(\mathbf{4}^{\text {th }}\right.$ \\
$\left.\mathbf{5}^{\text {th }} \mathbf{G}\right)$
\end{tabular} & $\begin{array}{l}\text { - Subset }\left(\mathbf{5}^{\text {th }} \mathbf{G}\right) \\
- \text { A or B }(A \cup B)\left(5^{\text {th }} \mathbf{G}\right)\end{array}$ \\
\hline
\end{tabular}

Note: $\mathbf{G}$ refers to the grade wherein the listed situation has been discussed within the textbook

\section{DISCUSSION}

Textbooks have an important role due to their great influence on the process of teaching and learning. Furthermore, Robitaille and Travers (1992) have cited the textbooks as a "significant factor in determining students' opportunity to learn, facilitating the transfer of educative contents in the function of the current curricula guidelines, and constituting a mean to learning”. Therefore, through analyzing primary school content of probability as it is acknowledged in the national textbook, the opportunity given to students to enhance their probabilistic reasoning can be interpreted.

According to Hacking (1975 as cited in Batanero et al., 2016), the probability was conceived from two main different perspectives. First, a statistical side which is relevant to the objective mathematical rules that govern random processes. Second, complementary to this vision, an epistemic side views probability as a personal degree of belief depends on the information available to the person assigning a probability. Using Hacking's explanation to look into the revealed results wherein four interpretations of probability have been discussed through the national textbook (intuitive, classical, experimental, and axiomatic). it's clear that most of the textbook's arguments have considered only the statistical side of probability through emphasizing the mathematical rules. However, the subjective meaning that defines probability as a personal degree of belief and can be updated with new information through Bayes theorem (Batanero, 2005 as cited in Gómez \& Miguel, 2014) hasn't been approached and seems to be ignored. This ignorance can affect students' probabilistic reasoning. Wherein in the multistructural and rational level of probabilistic reasoning, students should recognize the conditional probability (Mooney et al., 2014) which is considered a prerequisite for learning the subjectivist meaning of probability (Jones et al., 2007).

On the other hand, besides the absence of the subjective meaning of probability, there is also a lack of experimental meaning which has only appeared in $5^{\text {th }}$ Grade. Performing probability experiments encourages pupils to develop understandings of probability grounded in real events, as opposed to merely computing answers based on formulae (Andrew, 2009 as cited in Tsakiridou \& Vavyla, 2015). Therefore, the lack of experimental probability in contrast to emphasizing computing probability from 
a theoretical perspective can also affect students' probabilistic reasoning. As Konold (1995) stated, when teaching probability predominantly uses a theoretic approach rather than a frequentist one, pupils often develop conceptions about probability based on deterministic reasoning.

Complementary to the prior two points, two other crucial issues have been observed, which also may affect students' probabilistic reasoning. First, there is no connection between the four stated interpretations of probability. For example. In $3^{\text {rd }}$ grade, the textbook discourse doesn't clarify the relationship between one's personal expectation of an event (i.e., intuitive meaning) and how to quantify this expectation using theoretical probability. Second, the necessary conditions for implementing each interpretation of probability has not been treated. For instance, although, the sequence of the probabilistic content in $5^{\text {th }}$ grade seems logical and interrelated. there is no confirmation concerning the hypotheses that should be examined before operating both the experimental and theoretical law to calculate the probability of an event.

\section{CONCLUSION}

In conclusion, the primary school content of probability in Egypt intends to enhance students' deterministic reasoning through experiencing many probabilistic tasks from the classical and axiomatic perspective. Although, different interpretation of probability has been raised (i.e., intuitive, classical, frequentist, and axiomatic). There is neither logical connection nor smooth transition among these interpretations. Besides, there is a lack of addressing the frequentist approach and the subjective meaning of probability which considered a crucial concept for promoting students' probabilistic reasoning has not been discussed. Therefore, it's important to revise learning objectives of probability by affirming some basic probabilistic concepts (e.g., the law of large number and conditional probability). Furthermore, translate those concepts into textbook activities (e.g., comparing experimental distributions with expectations from theoretical models, using two-way tables and tree diagrams to learn conditional probability).

According to Batanero et al., (2016), the probabilistic reasoning includes the ability to identify random events; analyze conditions of such events and derive appropriate modeling assumptions; construct mathematical models for stochastic situations and explore various scenarios and outcomes from these models, and apply mathematical methods and procedures of probability and statistics. Therefore, the previously described critiques within the primary content of probability may hinder students' probabilistic reasoning as follows:

- the absence of the subjective interpretation of probability prevents students to reason according to the lately acknowledged data. Then, it affects their decision to determine the probability of an event. The scarcity of subjective meaning of probability contradicts with Godino, Batanero, and Cañizares (1987 as cited in Gómez \& Miguel, 2014) recommendations about presenting this meaning at primary school in an intuitive way.

- the misconnection between different interpretations of probability makes students think probability as just procedures to quantify their expectations, instead of understanding it as a process to construct a mathematical model for a stochastic situation. Furthermore, in the absence of the appropriate conditions to implement each interpretation of probability, students may confuse regarding which model is fitting to describe the random phenomena.

According to Innabi (2014, p.3) "Very little research on statistics has been conducted in the Arab world". Moreover, there is a need to change the educational community perception towards understanding statistics and its importance. Therefore, the study results consider an endeavor to shed light on statistics education research (probability in the current study) in the Arabian community. Furthermore, it can also give insights into the context of teacher education as Stylianides and Ball (2004) has declared understanding the content that policymakers recommend students given the opportunity to learn considers one possible approach for discussing teachers' knowledge. Consequently, deducting what teachers would need to know to successfully enact these opportunities in their classrooms.

\section{REFERENCES}

Andrew, L. (2009). Experimental probability in elementary school. Teaching Statistics, 31(2), 34-36. 
Batanero, C., Godino, J. D., \& Roa, R. (2004). Training teachers to teach probability. Journal of Statistics Education, 12(1). http://www.amstat.org/publications/jse/v12n1/batanero.html

Batanero, C. (2005). Significados de la probabilidad en la educación secundaria. RELIME. Revista latinoamericana de investigación en matemática educativa, 8(3), 247-264.

Batanero, C., Chernoff, E., Engel, J., Lee, H., \& Sanchez, E. (2016). Research on teaching and learning probability. In Research on teaching and learning probability ICME-13 Topical Surveys (pp. 133). Springer, Cham. doi 10.1007/978-3-319-31625-3_1.

Dvořáková, B., Giménez, J., Guzon, A., Hao, L., Inekwe, I., Mejía, B., Sánchez, M., Scott, P., Serradó Bayés, A., Spěvák, J., \& Teague, D. (2017). The Importance of Teaching Probability. A Brief produced at the Park City International Seminar Park City Mathematics Institute. https://projects.ias.edu/pcmi/hstp/sum2017/int/briefs/ImportanceofTeachingProbability.pdf

Falk, R., \& Konold, C. (1992). The psychology of learning probability. In F. S. Gordon \& S. P. Gordon (Eds.), Statistics for the twenty-first century (pp. 151-164). Washington: Mathematical Association of America.

Godino, J. D., Batanero, C., \& Cañizares, M. J. (1987). Azar y probabilidad. Fundamentos didácticos y propuestas curriculares. Madrid: Síntesis.

Godino, J. D. (2003). Teori'a de las funciones semio'ticas. Un enfoque ontolo'gico-semio'tico de la cognicio'n e instruccio'n matema'tica. Departamento de Dida'ctica de la Matema'tica. Universidad de Granada. (Available at http://www.ugr.es/ local/jgodino/indice_tfs.htm).

Gómez, E., and Miguel, J. (2014). Meaning of probability in Spanish curriculum for primary school. In K. Makar, B. de Sousa, \& R. Gould (Eds.), Sustainability in statistics education. Proceedings of the Ninth International Conference on Teaching Statistics (ICOTS9, July 2014), Flagstaff, Arizona, USA. Voorburg, The Netherlands: International Statistical Institute.

Hacking, I. (1975). The emergence of probability. Cambridge, MA: Cambridge University Press.

Innabi, H. (2014). Teaching statistics in the Arab countries: the ambitions and the needs. In K. Makar, B. de Sousa, \& R. Gould (Eds.), Sustainability in statistics education. Proceedings of the Ninth International Conference on Teaching Statistics (ICOTS9, July 2014), Flagstaff, Arizona, USA. Voorburg, The Netherlands: International Statistical Institute.

Jones, J. L., \& Tarr, J. E. (2007). An examination of the levels of cognitive demand required by probability tasks in middle grade mathematics textbooks. Statistics Education Research Journal, $6(2), 4-27$

Konold, C. (1995). Issues in Assessing Conceptual Understanding in Probability and Statistics. Journal of Statistics Education, 3(1).

Mooney E.S., Langrall C.W., Hertel J.T. (2014) A Practitional Perspective on Probabilistic Thinking Models and Frameworks. In: E. J. Chernoff \& B. Sriraman (Eds.), Probabilistic Thinking: Presenting plural perspectives (pp. 495-507). Dordrecht, The Netherlands: Springer.

Robitaille, D. F., \& Travers, K. J. (1992). International studies of achievement in mathematics. In D. A. Grouws (Ed.), Handbook of research on mathematics teaching and learning: A project of the National Council of Teachers of Mathematics (pp. 687-709). Reston, VA: NCTM.

Tsakiridou, H., \& Vavyla, E. (2015). Probability concepts in primary school. American Journal of Educational Research, 3(4), 535-540. https://doi.org/10.12691/education-3-4-21

Savard A. (2014) Developing Probabilistic Thinking: What About People's Conceptions?. In: E. J. Chernoff \& B. Sriraman (Eds.), Probabilistic Thinking: Presenting plural perspectives (pp. 283-298). Dordrecht, The Netherlands: Springer.

Stylianides, A. J. \& Ball, D. L. (2004). Studying the mathematical knowledge needed for teaching: The case of teachers' knowledge of reasoning and proof. In Annual Meeting of the American Educational Research Association, San Diego, CA. 